\title{
"One for all and all for one": consensus-building within communities in rural India on their health microinsurance package
}

This article was published in the following Dove Press journal:

Risk Management and Healthcare Policy

4 August 2014

Number of times this article has been viewed

\section{David M Dror ${ }^{1,2}$ \\ Pradeep Panda' \\ Christina May ${ }^{3}$ \\ Atanu Majumdar' \\ Ruth Koren ${ }^{4}$}

'Micro Insurance Academy, New Delhi, India; ${ }^{2}$ Erasmus University, Rotterdam, the Netherlands; ${ }^{3}$ University of

Cologne, Cologne, Germany; ${ }^{4} \mathrm{Tel}$ Aviv University, Ramat Aviv, Israel

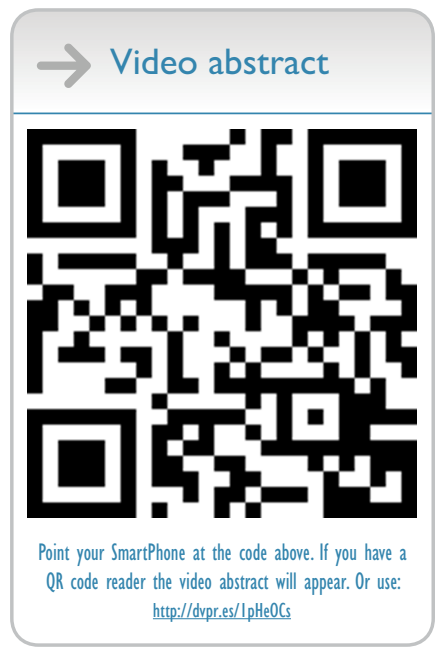

Correspondence: Pradeep Panda Micro Insurance Academy, 52-B, Okhla Industrial Estate, Phase III, New Delhi - I 10020, Delhi, India

Tel +9 I II 43799100

Fax +9| I| $43799 \mid 17$

Email pradeep@mia.org.in
Introduction: This study deals with consensus by poor persons in the informal sector in rural India on the benefit-package of their community-based health insurance (CBHI). In this article we describe the process of involving rural poor in benefit-package design and assess the underlying reasons for choices they made and their ability to reach group consensus.

Methods: The benefit-package selection process entailed four steps: narrowing down the options by community representatives, plus three Choosing Healthplans All Together (CHAT) rounds conducted among female members of self-help groups. We use mixed-methods and four sources of data: baseline study, CHAT exercises, in-depth interviews, and evaluation questionnaires. We define consensus as a community resolution reached by discussion, considering all opinions, and to which everyone agrees. We use the coefficient of unalikeability to express consensus quantitatively (as variability of categorical variables) rather than just categorically (as a binomial Yes/No).

Findings: The coefficient of unalikeability decreased consistently over consecutive CHAT rounds, reaching zero (ie, 100\% consensus) in two locations, and confirmed gradual adoption of consensus. Evaluation interviews revealed that the wish to be part of a consensus was dominant in all locations. The in-depth interviews indicated that people enjoyed the participatory deliberations, were satisfied with the selection, and that group decisions reflected a consensus rather than majority. Moreover, evidence suggests that pre-selectors and communities aimed to enhance the likelihood that many households would benefit from CBHI.

Conclusion: The voluntary and contributory $\mathrm{CBHI}$ relies on an engaging experience with others to validate perceived priorities of the target group. The strongest motive for choice was the wish to join a consensus (more than price or package-composition) and the intention that many members should benefit. The degree of consensus improved with iterative CHAT rounds. Harnessing group consensus requires catalytic intervention, as the process is not spontaneous.

Keywords: benefit-package design, micro health insurance, community-based health insurance, $\mathrm{CBHI}$

\section{Introduction}

In India, as in other low- and middle-income countries, most of the rural population lives and works in the informal sector. ${ }^{1,2}$ The implied consequence of being "informal" is that people are often engaged in small-scale, self-employed activities (with or without hired workers), typically unrecorded, unregistered and conducted without proper integration with the administrative machinery responsible for enforcing laws and regulations, usually escaping both the attention of and recognition from 
the authorities. ${ }^{3}$ Thus, they are excluded from market or social arrangements through which they might benefit from health insurance. ${ }^{4}$ Under these conditions, several development projects have been launched aimed at implementing health microinsurance at village or local level.5-11 Health microinsurance has originally been defined as a voluntary, contributory, community-based health insurance (CBHI) scheme for which the group designs the benefits, premiums, and/or governance structure, to be relevant and affordable to the local population. ${ }^{12,13}$ Different authors have used other names for the generic "microinsurance", eg, Micro Health Insurance (MHI), Mutual Health Organizations (MHO) (in French Mutuelles de santé), CBHI, Community-based Health Funds (CBHF), Community Owned and Operated Plans (COOP) etc. The difference between these names is not discussed in detail in this paper, and we use the generic "microinsurance" for all kinds of systems versus CBHI to refer to a people-centered mutual aid scheme. This definition departs from classical demand theory, which views the individual as formulating demand; here, the group defines the demand and ideally pools both risks and resources to provide protection to all members. ${ }^{14}$ This formulation of demand relies on mobilization of collective action.

The questions that beg empirical evidence are whether and how rural poor without prior experience with health insurance can be engaged in a complex process of selecting a coherent benefit-package that will reflect their communal needs and priorities, rather than simply being told to buy cheap insurance. Involving the rural community means empowering them to define the benefit types that would be payable to insured persons, as well as all the rules on deductibles, co-payments, cost-sharing amounts (thresholds), or maxima (caps), and other conditions and limitations which may determine the share of health-care cost that will be borne by the insurance (and in our context, by the microinsurance or CBHI scheme). The working assumption underlying this research question is that when rural groups are involved, they can reach consensus on the composition and price of the benefit-package that reflects local notions of value-formoney, leading to stronger motivation to enroll.

Literature on consumers' preferences for health insurance plans has so far concentrated on rich countries. ${ }^{15-21}$ Only few publications deal with the health insurance benefit choices of low-income persons in low-income countries. ${ }^{22-24}$ Dror et $\mathrm{al}^{25}$ and Danis et $\mathrm{al}^{26}$ described simulation exercises (called "CHAT" - Choosing Healthplans All Together) in which rural poor in India were asked to compose health insurance packages by selecting benefit types that should be included within a severe budgetary limitation. The main lessons from those experiments were that rural poor were interested in broad coverage rather than coverage of only rare events.

Following on from those experiments, a 5-year EC-FP7 project (2009-2014) on implementation of CBHI was launched by the Micro Insurance Academy (MIA), New Delhi ${ }^{27}$ (http://www.microinsuranceacademy.org) in three locations in rural India (Pratapgarh and Kanpur-Dehat districts, Uttar Pradesh, and Vaishali district, Bihar). ${ }^{28}$ The MIA implementation model enables prospective members to be involved in decisions on the benefit-package that the CBHI schemes offer. ${ }^{29}$ The prospective members selected pre-composed packages (rather than composing packages from a selection of benefit types, as was done under the earlier CHAT exercises) as well as premium levels that such packages commanded. The project unfolded in cooperation with field-partner non-governmental organizations (NGOs): BAIF (Bharatiya Agro Industries Foundation) in Pratapgarh; Shramik Bharti in Kanpur-Dehat; and Nidan in Vaishali, and the implementation aimed at enrolling rural women that participate in self-help groups (groups of 10-15 women saving together and giving each other loans from their common fund) (SHGs) facilitated by these field partners. These SHGs aim at economic and social empowerment and capacity building for women through micro-credit and other activities, with the intention to ultimately benefit the whole community. ${ }^{30}$ Both CHAT and the $\mathrm{CBHI}$ schemes also possess empowering features, as they allow local communities to exercise more control over decisions relating to health insurance. ${ }^{31}$ Additionally, by targeting women in CHAT activities, the implementing partners aim at enhanced participation of women in economic and social spheres. In this context, MIA understands its role as both a catalytic actor and facilitator of the process through which the $\mathrm{CBHI}$ is introduced to the communities with the help of field partners, and aiding the establishment of the local schemes. ${ }^{32}$

The setting of the present study was the implementation of these three CBHI schemes. The purpose of this article is to describe the process of involving rural poor in benefit-package design, explaining the underlying reasons for choices they made, and assessing their ability to reach group consensus regarding package composition, against the background of the research question formulated earlier.

The article includes a section describing the data and methods, followed by a section presenting the results from three choice exercises. We then discuss the ramifications of those insurance choices. Finally, we formulate conclusions and policy recommendations. 


\section{Data and methods \\ Data}

The study is based on four sources of data: a dataset obtained through a baseline study, CHAT exercises, in-depth interviews, and evaluation interviews. In accordance with the guidelines issued by the Indian Council of Medical Research, the overall study as well as the specific data collection tools used were checked and approved by the ethics committee of the University of Cologne, Germany. ${ }^{33}$

\section{Baseline study}

The source data for actuarial calculations of premiums of different benefits originates from a baseline survey of the 5-year project, conducted March-May 2010 in three locations in rural India. The selection criterion of households for inclusion in the sample was that at least one female member was enrolled in an SHG, affiliated with the field partner NGO in March 2010. The calculation of incidence of illness and premiums for each location was based on the entire sample at that site. Table 1 contains the detailed information on the sample, by location. More information on the context of the study is provided in Table S1.

\section{CHAT exercises data}

Group choice exercises were conducted in which female SHG groups were invited to "play CHAT" with the help of pictorial boards showing different benefit-packages and the related premium (a picture of a CHAT board is reproduced in Figure S1). CHAT involved different benefit-packages in each of our three study sites, developed in benefit-package selection workshops that are described in detail in the Findings section. The premiums for each of the benefit options were calculated by using the baseline data. The group discussions were led by $6-8$ facilitators in each location (some chosen from the SHG members and some from the field partner organization). These facilitators received training from the MIA. The CHAT games were conducted in three rounds: during the first

Table I Treatment and control households by location (20I I)

\begin{tabular}{llll}
\hline Location & Treatment & Control & $\begin{array}{l}\text { Total } \\
\text { households }\end{array}$ \\
\hline Pratapgarh (Uttar Pradesh) & 433 & 850 & 1,283 \\
Kanpur-Dehat (Uttar Pradesh) & 378 & 661 & 1,039 \\
Vaishali (Bihar) & 524 & 839 & 1,363 \\
Total households & 1,335 & 2,350 & 3,685 \\
\hline
\end{tabular}

Notes: Treatment households are the SHG households that were offered the option to join the $\mathrm{CBHI}$ in $20 \mathrm{II}$, and control households are the remaining SHG households who were not offered the option to join at that point in time.

Abbreviations: $\mathrm{CBHI}$, community-based health insurance; SHG, self-help group. round (CHAT 1) female participants from the SHGs were asked to select the benefit-package that met their and their families' needs (using colored stickers to denote their first and second priority). At the end of this individual round, each participant could take home a personal copy of the CHAT board to discuss the choices with family members. The next day, during the second round (CHAT 2), a facilitated group discussion was convened, in which each female SHG discussed the consequences of the choices, and the entire group was requested to select the one option that reflected the group's first choice, and an alternative second choice. The facilitators kept a record (on a predesigned "CHAT Data Capturing Form") of both individual and consensus choices made in CHAT 1 and 2. The third round (CHAT 3) took place about 15 days later, and its purpose was to select a single package that would be offered by the CBHI to all its potential members; the decision-rule was that each female SHG selected one package (similar to what was done in CHAT 2), and the package that was chosen by most groups was retained in each location. All the community members that facilitated the CHAT rounds did not get any pay or incentive for participating; and the facilitators from the field partner NGOs conducted the sessions as part of their normal work duty. Table 2 provides the number of groups and individuals who participated in CHAT exercises in each site.

\section{Individual in-depth interviews}

With the view to understanding the motivations underlying CHAT choices, we followed a mixed-methods methodology using both qualitative, open-ended in-depth interviews, and quantitative, closed-ended evaluation questionnaires. By doing that, we not only got a better picture on the reasons for the choices made, but also an understanding of the underlying processes. In-depth interviews were conducted with six female SHG members (in their households) in each of the three sites (Pratapgarh in November 2010, Vaishali in December 2010, and Kanpur-Dehat in

Table 2 Number of groups and individuals that participated in the CHAT exercises

\begin{tabular}{llll}
\hline & Pratapgarh & Kanpur-Dehat & Vaishali \\
\hline $\begin{array}{c}\text { CHAT I } \\
\text { Individual }\end{array}$ & 383 & 272 & 436 \\
$\begin{array}{l}\text { CHAT 2 } \\
\text { Group }\end{array}$ & 47 & 29 & 49 \\
$\begin{array}{l}\text { CHAT 3 } \\
\text { Group }\end{array}$ & 47 & 29 & 49 \\
\hline
\end{tabular}

Abbreviation: CHAT, Choosing Healthplans All Together. 
March 2011). At each site, we chose three SHGs which had been selected to be offered insurance and to participate in CHAT, and interviewed two members from each group. We decided to use individual interviews instead of group interviews to enable the women to openly voice negative impressions related to the group's decision-making process. Additionally, we conducted interviews with two CHAT facilitators per site to understand the facilitators' perspectives on the CHAT process and decision-making in the groups. In total, we conducted 24 interviews $([6+2] \times 3)$. All interviews were conducted in the local language (Hindi), tape-recorded, and later transcribed and translated into English. The interviewers were trained in using two different sets of semistructured questionnaires (one for SHG members and one for CHAT facilitators) that contained both exploratory and targeted questions inquiring, among other things, about experiences with and perception of CHAT, problems encountered during CHAT, decision-making processes in group and household, and reasons for particular choices. Answers to these questions were then compared using NVivo ${ }^{\circledR}$ (QSR International, Melbourne, Australia) software, version 8. We followed the method for directed qualitative content analysis described by Hsieh and Shannon, ${ }^{34}$ combining deductive and inductive coding of data.

\section{Evaluation questionnaires}

We additionally conducted structured, closed-ended evaluation interviews with about $20 \%$ of the households that participated in CHAT. The main purpose of these interviews was to evaluate the awareness campaign wherein CHAT was one component. ${ }^{35}$

\section{Identification of benefit-package options}

The first step in the process of benefit-package design entailed preparing a limited set of options which would be presented to the groups for selection through the CHAT exercise. This was done through an interactive exercise (called "Benefit-package selection workshop") facilitated by MIA, in which representatives of the field partners and of the communities (the SHG federation, SHG members, and community leaders, eg, teachers, panchayat members, and community health workers) reviewed all the pertinent information about morbidity, costs of care, health-seeking behavior, and availability of health-care facilities (obtained through the baseline study). The discussions revolved around several benefit-package options and the premium (the premium [per person per year] is calculated using the basic formula: Pure risk premium $=$ [average expenditures per episode] $*$ [incidence rate] assuming a Poisson distribution of incidence and truncating frequency distributions of expenditures to take account of including thresholds and caps in the insurance coverage) that each package would command (community rated per person per year). The output of each workshop was four to six packages that would be presented to the entire target population for selection.

\section{Method of measuring consensus: coefficient of unalikeability}

We define consensus as "general agreement/resolution arrived at by most of those concerned, after everyone's opinions are heard and understood, and a solution is created that everyone agrees to". This definition is in line with the approach used by Sultana and Thompson ${ }^{36}$ and Mohammed and Ringseis. ${ }^{37}$ We apply "unalikeability", meaning "how often observations differ from one another" to measure the consensus reached within each location. ${ }^{38}$ Unalikeability is expressed as a coefficient that measures variability of the categorical variable "the package that people chose". Each package was numbered (see package numbers in Table 3). The choices of every participant were noted in each session and compared with those of other individuals in the same location; individuals were matched to others through a random process of pairing. For each pair, we noted whether the choices were identical (denoted 0) or not (1). By using the techniques of combinatorics we counted all the observations that differed (by Excel $^{\circledR} 2010$ [Microsoft Corporation, Redmond, WA, USA]). The value of the coefficient lies between 0 and 1 , where 0 indicates that all observations within the set are identical and 1 means that all observations differ from each other. If the coefficient of unalikeability decreased over consecutive sessions, we concluded that the differences within the cohort were decreasing, and the zero value of the coefficient of unalikeability meant that complete convergence was reached on a particular package. We preferred this method over Kappa statistics, which is used for measuring reliability of judgment (especially useful when agreement is sought on something rare). Kappa statistics usually involves agreement or disagreement of observers on one event, which is different from the CHAT exercises, where many persons need to select one item from a set of multiple items. Table S2 shows the computation of the coefficients with first and second choices in the three locations.

Kader and Perry ${ }^{38}$ did not discuss any statistical properties of the coefficient of unalikeability, but since the coefficient is calculated from the frequency distribution of choices, we calculated the significance of differences of the coefficients by estimating 
Table 3 Options retained at the benefit-package selection workshops, and the package selected during CHAT (in INR unless a different unit is stated)

\begin{tabular}{|c|c|c|c|c|c|c|c|c|c|c|c|c|c|c|c|c|}
\hline \multirow{2}{*}{$\begin{array}{l}\text { Benefit typel } \\
\text { package }\end{array}$} & \multicolumn{4}{|c|}{ Pratapgarh } & \multicolumn{6}{|c|}{ Kanpur-Dehat } & \multicolumn{6}{|c|}{ Vaishali } \\
\hline & I & 2 & 3 & 4 & $\mathbf{I}$ & 2 & 3 & 4 & 5 & $6^{a}$ & $\mathbf{I}$ & 2 & 3 & 4 & 5 & 6 \\
\hline Lab test (PPPY) & - & - & - & - & - & - & - & - & - & - & 200 & 200 & 100 & 200 & 200 & 100 \\
\hline Imaging (PPPY) & - & - & - & - & - & - & - & - & - & - & 300 & 300 & 200 & 300 & 300 & 200 \\
\hline Wage loss (per day) & 100 & 100 & & 100 & 75 & 100 & 75 & 100 & 75 & 100 & 0 & 100 & 100 & 0 & 100 & 100 \\
\hline $\begin{array}{l}\text { From day (numbers } \\
\text { represent days) }\end{array}$ & 3 & 3 & & 3 & 4 & 4 & 4 & 4 & 4 & 4 & & 4 & 4 & & 4 & 4 \\
\hline $\begin{array}{l}\text { To day (numbers } \\
\text { represent days) }\end{array}$ & 8 & 8 & & 8 & 13 & 13 & 13 & 13 & 13 & 13 & & 9 & 9 & & 9 & 9 \\
\hline $\begin{array}{l}\text { Consultation with } \\
\text { medicine } \\
\text { Hospitalization }\end{array}$ & - & - & - & - & Yes & Yes & Yes & Yes & Yes & Yes & Yes & Yes & Yes & Yes & Yes & Yes \\
\hline PPPY & 5,000 & 5,000 & 6,800 & 6,000 & 3,000 & 4,000 & 5,000 & 6,000 & 7,000 & 4,500 & & & 2,000 & & & 2,000 \\
\hline $\begin{array}{l}\text { Per family per year } \\
\text { Hospitalization for }\end{array}$ & 3,000 & 3,000 & 3,000 & 5,000 & & & & & & 25,000 & & & & & & \\
\hline $\begin{array}{l}\text { C-section } \\
\text { Deduct (payable } \\
\text { by govt) }\end{array}$ & $\mathrm{I}, 400$ & $\mathrm{I}, 400$ & $\mathrm{I}, 400$ & $\mathrm{I}, 400$ & & & & & & & & & & & & \\
\hline Transportation & - & 200 & & 100 & 100 & 100 & 150 & 150 & 200 & 100 & & & & & & \\
\hline Natural death & & & & & & & & & & & & & & 30,000 & 30,000 & 30,000 \\
\hline Accidental death & & & & & & & & & & & & & & 75,000 & 75,000 & 75,000 \\
\hline $\begin{array}{l}\text { Disability due to } \\
\text { accident }\end{array}$ & & & & & & & & & & & & & & 37,500 & 37,500 & 37,500 \\
\hline Premium per persc & n per $y$ & ear (in & INR) & & & & & & & & & & & & & \\
\hline PPPY - family up to 5 & 157 & 162 & 176 & 176 & 192 & 221 & 243 & 270 & 290 & 192 & 187 & 197 & 236 & $\mathrm{I}, 287$ & 197 & 236 \\
\hline PPPY - family 6-8 & 157 & 162 & 176 & 176 & 192 & 221 & 243 & 270 & 290 & 192 & 178 & 188 & 225 & 1,278 & 188 & 225 \\
\hline $\begin{array}{l}\text { PPPY - family 9+ } \\
\text { Life premiums }\end{array}$ & 157 & 162 & 176 & 176 & 192 & 221 & 243 & 270 & 290 & 192 & 160 & 169 & 203 & 160 & 169 & 203 \\
\hline PPPY I person & & & & & & & & & & & & & & 100 & 100 & 100 \\
\hline PPPY 2 persons & & & & & & & & & & & & & & 50 & 50 & 50 \\
\hline PPPY 3 persons & & & & & & & & & & & & & & 67 & 67 & 67 \\
\hline PPPY 4 persons & & & & & & & & & & & & & & 50 & 50 & 50 \\
\hline PPPY 5 persons & & & & & & & & & & & & & & 40 & 40 & 40 \\
\hline PPPY 6 persons & & & & & & & & & & & & & & 33 & 33 & 33 \\
\hline PPPY 7 persons & & & & & & & & & & & & & & 29 & 29 & 29 \\
\hline PPPY 8 persons & & & & & & & & & & & & & & 25 & 25 & 25 \\
\hline PPPY 9 persons & & & & & & & & & & & & & & 22 & 22 & 22 \\
\hline PPPY 10 persons & & & & & & & & & & & & & & 20 & 20 & 19 \\
\hline Package chosen & & & & $* * *$ & & & & & & $* * *$ & & $* * *$ & & & & \\
\hline
\end{tabular}

Notes: aPackage number 6 in Kanpur-Dehat district was not designed in the original workshop; instead, it was created after feedback from the community, which wanted a higher cap for individual hospitalizations. Based on the package originally chosen by the groups in CHAT - package I - a new package entailing basically the same benefits and the same price but a family floater instead of an individual cap was designed and then agreed to by the community. ****Indicates the package that was chosen in the respective locations from among the options considered.

Abbreviations: CHAT, Choosing Healthplans All Together; govt, government; PPPY, per person per year; INR, Indian Rupee.

the significance of difference between the distributions under different settings, by employing the chi-square test.

\section{Findings}

\section{The benefit-package options considered}

The options that were retained in the benefit-package selection workshops were presented to the target population in the different CHAT rounds and drawn as "CHAT boards" (Figure S1). The data are shown in Table 3.

We used the coefficient of unalikeability to measure the variability of choices made. We observed that the coefficient of unalikeability decreased over consecutive CHAT rounds in all locations, indicating that groups gradually adopted a consensus on one package. Incidentally, groups in all three locations converged towards consensus also on their second priority package (data not shown). The differences in the values of the coefficients of unalikeability were significant $(P<0.000)$.

The data in Figure 1 clearly shows that consensus was higher in CHAT 2 than in CHAT 1, and increased further in CHAT 3. CHAT 3, like CHAT 2, was a group choice, which took place 15 days after CHAT 2, and following 


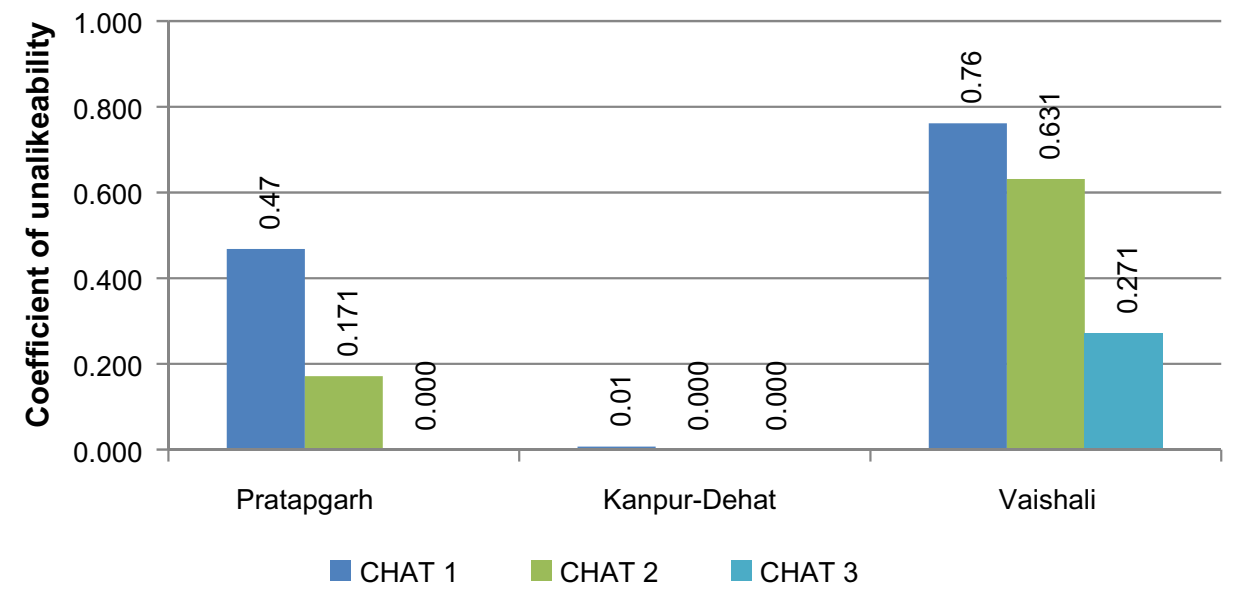

Figure I Coefficient of unalikeability in three CHAT rounds and three locations. Abbreviation: CHAT, Choosing Healthplans All Together.

discussions that each individual had with others in her household and community. One might have expected that external influences from people that did not participate in the deliberations in the SHGs would reduce consensus; however, the coefficient of unalikeability decreased, implying that consensus had actually increased after interactions with outsiders. This finding clearly indicates that the consensual choice was not limited only to persons that participated in the CHAT exercises, but reflects the views of the entire target population in each location on the desirable benefitpackage for them.

After the CHAT rounds, we conducted structured closed-ended evaluation interviews with about $20 \%$ of

Table 4 Why people chose the package they did

\begin{tabular}{llll}
\hline & Pratapgarh & $\begin{array}{l}\text { Kanpur- } \\
\text { Dehat }\end{array}$ & Vaishali \\
\hline $\begin{array}{l}\text { No of respondents } \\
\text { CHAT 2 }\end{array}$ & 115 & 72 & 104 \\
$\begin{array}{l}\text { Participated in CHAT 2a } \\
\text { Reasons for choosing the final package (among }\end{array}$ & 80.9 & 72.2 & 72.1 \\
Other SHG members liked it & 25.8 & 25.0 & 24.0 \\
Cheapest & 20.4 & 32.7 & 26.7 \\
Best & 21.5 & 21.2 & 25.3 \\
Most benefits & 22.6 & 3.8 & 14.7 \\
Other & 9.7 & 17.3 & 9.3 \\
CHAT 3 & & & \\
Participated in CHAT 3 & 73.9 & 62.5 & 62.5 \\
Reasons for choosing the final package (among participants) $)^{\mathrm{b}}$ & \\
Other SHG members liked it & 35.3 & 33.3 & 33.9 \\
Cheapest & 24.7 & 28.9 & 27.7 \\
Best & 12.9 & 24.4 & 21.5 \\
Most benefits & 25.9 & 8.9 & 12.3 \\
Other & 1.2 & 4.4 & 4.6 \\
\hline
\end{tabular}

Notes: aPercentage of the respondents; ${ }^{b}$ percentages of those that participated in CHAT 2 or 3 , respectively.

Abbreviations: CHAT, Choosing Healthplans All Together; SHG, self-help group. the participants, who were asked about the main reason for their choice in CHAT 2 and in CHAT 3. The results are shown in Table 4. Interestingly, at the CHAT 2, about one-quarter of the respondents in all locations said that they wanted to be part of a group choice and therefore chose the package that "other SHG members liked". The three other reasons (cheapest, best, or most benefits) had different weights across the locations. But in CHAT 3, the consensus was dominant in all locations. When all three cohorts were aggregated, increase in the preference for consensus choice was significant $(P=0.037$, chi-squared test).

We conducted in-depth interviews with female SHG members that participated in CHAT and with a few facilitators and cite here their testimonials, as addition to the quantitative information.

In general, respondents expressed their satisfaction with the benefit-package selection process:

I like that type of game. Everything in that game was to be praised. [SHG member 5, Kanpur-Dehat]

We liked the method, we liked pasting the stickers.

[SHG member 2, Vaishali]

[The CHAT exercise] was very good and we all liked it very much. [SHG member 2, Pratapgarh]

According to one facilitator, CHAT encouraged the participation of all SHG members and their families in the decision-making process:

Usually in our group meetings [...], people listen to these things silently and nod their heads, but in this CHAT game, there was participation from all women. [...] The family members also joined, so this is indeed a good method. [Facilitator 1, Vaishali] 
People enjoyed the participatory nature of the CHAT exercises, liked the deliberations, and liked to make their own decisions:

The best thing in the CHAT was that the women were free to choose any package that they liked. It was not imposed on them, and there were no restrictions or obligations to choose a particular package. [Facilitator 2, Pratapgarh]

The data from our in-depth interviews also confirm that group decisions reflected a consensus rather than majority decision. Respondents described the discussions that occurred and how their opinions were considered:

[The choice] was a consensus and our opinions were entertained. [SHG member 2, Vaishali]

We all discussed and everyone agreed to it. [SHG member 3, Vaishali]

It was a collective decision. [SHG member 5, Vaishali]

They [the other SHG members] were discussing [...] which package should be chosen and which one is better for us. Every person decided that there would be one insurance for all. [SHG member 2, Kanpur-Dehat]

There was discussion in which some said that package number 4 is best. Then we all favored it as well. [...] After the discussion [...] we all agreed. [SHG member 1, Pratapgarh]

Corresponding to the evaluation interviews, which showed that respondents chose packages other SHG members liked, we found qualitative evidence in all locations that people often looked up to trusted peers in their groups and considered their choices. For instance, in Pratapgarh, one member said:

Knowledgeable people know their benefits; what is right or what is wrong. Everyone selected the same package. [SHG member 4, Pratapgarh]

And in Vaishali, one facilitator explained:

Everybody believes in the secretary of the group. Whatever the decision the secretary will take, that will be important.

Anyhow everybody gives her opinion but the chairman's opinion is most important. [Facilitator 2, Vaishali]

However, respondents did not simply copy the decisions or opinions of administrative officers. Everyone's opinion was entertained and considered as important, as explained in the following testimonial:

Everyone's suggestion has equal importance in the groups. This is all about the groups, that everyone has to go together and [has to take] care of each other's interest. [Facilitator 2, Kanpur-Dehat]

It is recalled that as part of the decision-making process, participants in the CHAT 1 took home a copy of the CHAT boards in order to validate choices and obtain support from family and friends. Several interviewees mentioned the value of these consultations:

After CHAT 1, we gave everybody the CHAT board to discuss all the possibilities with family members. [...] They showed the board to the male members of the family. After that, heads of different families discussed how to deal with it. As the women cannot do all the work, they rely on the head of the family or those who they consider the head of the locality like the teacher or the doctor. [...] When they approve the same, then the women can pursue the matter.

[Facilitator 2, Kanpur-Dehat]

Nevertheless, this interaction was not always easy and sometimes necessitated additional explanations from other SHG members or NGO staff to convince family members:

[During CHAT in the group] everything was good, [...] but when they shared with their respective homes, they were criticized by some family members. [...] It was resolved when the person who criticized was convinced by others, so they understood everything about it. [SHG member 1, Kanpur-Dehat]

Clearly, even though the women were empowered to make choices in the CHAT exercises, it was essential to also secure the agreement of the men in order to enable the women to actually confirm the choice and later actually enroll and pay:

[...] [T]he decision is taken by the male guardian or the husband in the family, since it is a matter of money. Unless [they] were not told by the family guardian [women] cannot pay the instalments. They said that the way in which they are conducting the meetings with the women of the group, in the same way there should be meeting with other family members, guardians and head of the family, to convince them. [Facilitator 2, Pratapgarh]

In summary, our evidence shows that in all locations, the target population was keen to converge towards consensus. Local leaders, knowledgeable persons, and male household heads influenced the discussion and the decision-making process, and wanted to be involved in more detail. 


\section{The benefit-packages chosen}

The pre-selectors in the three locations seemed to have different perceptions of the main issues that the population was facing. In Vaishali, the pre-selectors suggested three patterns: one that included hospitalization and outpatient care, another which focused mainly on outpatient care, and the third which included these health packages plus life insurance. The community rejected the life insurance option, and of the two health options, it favored the outpatient model but included wage-loss compensation in case of hospitalization, and chose the option commanding higher premiums. This community could take advantage of government-provided hospitalization insurance for people below the poverty line (RSBY, Rashtriya Swasthya Bima Yojana), which probably explains why they did not retain hospitalization benefits.

In Pratapgarh, the pre-selectors retained benefit-packages covering hospital-related care: hospitalizations, wage-loss during hospitalizations, and transportation to hospital, as well as coverage of delivery with C-section. In this region, RSBY was almost nonexistent when the CBHI was implemented. This group enhanced the likelihood of claims by many members when it added a benefit related to maternity which is not otherwise available free of charge.

In Kanpur-Dehat, the pre-selectors proposed a combined set of benefits covering both hospitalizations and outpatient consultations; the target population reached consensus on the premium level, but wanted a different set of benefits that would enhance intra-household cross-subsidization.

\section{The intention to choose a package that will benefit many members}

We observed that both the pre-selectors and the community employed different strategies to enhance the likelihood that many households would benefit from CBHI.

In Vaishali, the pre-selectors proposed a decreasing premium per person as household size increases. This arrangement was a de-facto cross-subsidy from smaller households to larger ones, and the groups in Vaishali confirmed their agreement to this intra-group subsidy. Indeed, $14 \%$ of the enrolled families, which actually comprised $24 \%$ of the total enrolled individuals, benefited from this discount in Vaishali. Of the families with family sizes between six and eight (average 6.35), 13\% got a discount of $5 \%$, and $1 \%$ of the families with family size nine and above (average 9.33) paid $15 \%$ less than the base premium. As for package composition, this community chose mainly outpatient care benefits that are more likely to be claimed by many members.
In Kanpur-Dehat, the group accepted the benefit types proposed by the pre-selectors, but requested a change in the terms applying to hospital benefits, so that the cap would apply to a household rather than to each individual separately. This was labelled "family floater", which means that within a cap per family and per event (rather than a cap per person per year), one household member can claim more than one event per year. This arrangement institutionalizes intra-household cross subsidization and adds welfare to the most vulnerable members, as well as to the non-claiming household members (that are released from the obligation to pay for repeat hospitalization of close relatives). In addition, the combination of inpatient and outpatient benefits increased the likelihood of claiming a benefit by many insured members.

As already mentioned, some respondents chose a particular package because it was "cheapest" or had "most benefits" (Table 4). We bring a few testimonials to shed more light on the considerations that influenced the choices made, especially in Kanpur-Dehat and Pratapgarh:

I was going for [the more expensive package] but which may be difficult for other members. Hence I joined the collective decision to accommodate others, as all the others have to benefit. [SHG member 4, Kanpur-Dehat]

This indicates that when discussing the price, the participants were concerned not merely about their ability to pay, but of other members as well. The two facilitators in Kanpur-Dehat observed the same behavior pattern:

Everyone selected packages for themselves keeping in mind their own benefits [...] But when they met among themselves and were informed that a single package is applicable for the whole group they realized that $[. .$.$] they all should$ select a package that is affordable for all. [Facilitator 2, Kanpur-Dehat]

Additionally, SHG members in Kanpur-Dehat chose to go for the cheapest option to "test" CBHI, which was a new concept for the community, as explained by a facilitator:

Wherever we visited, everyone used to say that they want to opt for the minimum one for the first year. If we benefit then we may look for the better one next year. [Facilitator 2, Kanpur-Dehat]

In Pratapgarh, our in-depth interviews revealed that CHAT participants often set benefits in relation to price and opted for package 4 after realizing that it cost only slightly more but offered more benefits than other packages. It was especially important for them that packages 4 and 2 (their first and second 
choice) were "broader" than the other packages (ie, offered a higher variety of benefits). This shows that they did not simply assume that the most expensive package would provide the most benefits. Otherwise, they would have chosen package 3 over 2. Instead, they preferred a package with most benefit types with lower caps over few benefit types with higher caps.

In Kanpur-Dehat, the selection emphasized insuring minor illnesses and outpatient care. A facilitator in KanpurDehat described how households which had experienced hospitalization in the past first favored expensive packages with more hospital coverage. However, the community chose cheaper packages, reflecting that most would not need to be hospitalized but would need coverage of outpatient care for minor but frequent illnesses:

The people selected the packages keeping in mind their own experience. [...] Though there were some people who wanted to get more benefits with the large packages, most people wanted to start with the small package, keeping in mind that very few people do visit the hospitals and most of the people prefer to visit the local doctors. [Facilitator 1, Kanpur-Dehat]

In Pratapgarh, where outpatient care was not included in any of the packages offered, some interviewees criticized the choice of the pre-selectors to include only inpatient coverage:

There are several issues here [...] they have not included minor ailments and the benefits in case of Caesarian section only. If one is delivering normally, then nothing will be paid. [SHG member 2, Pratapgarh]

Generally, respondents in all three sites expressed their satisfaction with the final package chosen:

We are fully satisfied with [our choice]. [SHG member 2, Pratapgarh]

Everybody is satisfied [with the package we have chosen]. [SHG member 1, Vaishali]

We are very satisfied with [the package we have chosen]. [SHG member 5, Kanpur]

\section{Discussion}

This article deals with benefit-package design for $\mathrm{CBHI}$ in rural and informal settings in India. The CBHI model discussed here is characterized by voluntary and contributory affiliation, in which the entire group is encouraged to join en bloc. These new conditions of introducing health insurance include a more meaningful and engaging experience of customers directly with the design of the benefit-package, based on exchanges with others, rather than deciding in isolation, and emphasis on a group solution which addresses perceived priorities of the target group that the community is best placed to validate collectively rather than any individual alone. This process is much more sophisticated than expecting a decision merely on the merit of an unverifiable claim that premiums are low, and the relationship with the insurance to end, not begin, once people pay the premium.

The implementation model relies on collective action to select the benefit-package, which determines the share of health-care costs borne by the CBHI. We explored previous studies of how collective action was mobilized effectively. Ostrom ${ }^{39}$ pointed to extensive fieldwork that established that individuals voluntarily organize to provide, inter alia, mutual protection against risk. She added that typically when people engage in direct communications with each other, they can generate cooperative behavior or create a social norm that has a certain staying power in encouraging the growth of cooperative behavior over time. Cooperative behavior thrives on a process that leads to implementation of changes (which in our study entailed a decision on a benefit-package that would be implemented by the CBHI schemes). Consensus magnifies the buy-in of decisions, but there is some debate on whether consensus means unanimity of opinions or involving everybody in the same process (with possibly a large majority of identical opinions). We have shown that consensus can be expressed quantitatively rather than just categorically (as a binomial Yes/No), and that the degree of consensus improved through an iterative process of decision-making. The salient lesson from this study is that the wish to be part of the consensus was the most important motive for choice of benefitpackage (Table 4), more than the price or the composition of the package. Another important insight is that there is no contradiction in saying that each community can agree on the application of one and only one package to everybody in that community, while also saying that communities living in different conditions choose different packages. The three communities reached consensus, which was to select a package that reflected different morbidity patterns, socioeconomic statuses or available health-care services. The similarity was the process of consensus building, and the difference was the actual package. This finding corroborates previous claims that one size cannot fit all locations but a similar decision process can. ${ }^{40}$ The similarity was in a descending value of the coefficient of unalikeability over subsequent iterations of the facilitated choice exercise (Figure 1) and in the motivation mentioned by many to join a consensus (Table 4). 
The finding that individuals chose packages that can enhance benefits to their community is interesting from a perspective of theory of demand. Conventional insurance demand theory posits that demand decisions are made by individuals on the basis of their perceived marginal utility from the purchase of insurance. ${ }^{41,42}$ In the CBHI model described, the balance between self and community interests was achieved by starting the process with a phase of individual choice of package, followed by face-to-face exchanges with other community members in small groups. The consensus of small groups (composed of women that participate in SHGs) was then shared with their family members, and the facilitation given to women to discuss their choices with family and community members created an opportunity to discuss why other participants preferred different choices, recognize the legitimacy of other opinions, and seek a way to devise a compromise consensus. The discussions were then repeated with members of other groups in the same community who also elaborated their consensus in a similar process, and the follow-up discussions led to higher consensus. Our evidence corroborates the results of Mohammed and Ringseis ${ }^{37}$ that consensus building is gradual and requires multiple iterations with frequent face-to-face informal exchanges between community members. Our participatory process generated high satisfaction with the process and with the resultant benefit-package, as attested by the testimonials. More importantly, participation in the CHAT process was instrumental in enhancing understanding of the insurance process in the context of CBHI, which was positively associated with higher enrolment. ${ }^{35}$ As such, the process can serve to scale penetration of insurance in rural settings in India, by creating more awareness, leading to more trust, which in turn leads to higher enrolment.

An important common denominator of the choice process in all three locations was its inclusive nature and the intention to enhance the likelihood that many members of the community should benefit from the CBHI. Additionally, community leaders who participated in the benefit-package selection workshop enhanced the probability that households will be able to cope with multiple episodes within the household (Vaishali) and ensured that poorer households would be able to participate in CBHI by offering discounts for large households (Vaishali) or by choosing cheaper packages affordable to everyone, with the "family floater" cap (Kanpur-Dehat). Some of these novel provisions have been either initiated or confirmed by consensus of the large grassroots groups, so that there can be no doubt that they were able to understand the welfare-enhancing potential of these arrangements. We therefore conclude that the demand for $\mathrm{CBHI}$ in the informal sector in rural India is based in large part on collective priorities, and on the general understanding that if most people did not like the package on offer, there would be no CBHI at all for anybody.

The CHAT process specifically involved women organized in SHGs. In CHAT 1, they made their choices independently from other family members. Although it was reported that men would finally decide whether to join CBHI, our data also show that when male household heads provided feedback on choices women made in CHAT 1, most men generally agreed. On the other hand, when women had difficulty explaining their CHAT choices to their family or getting agreement, they were supported by the NGO staff to convince family members. Clearly, each woman commanded a different degree of authority and empowerment within their household. Baily ${ }^{43}$ reported that women needed male guardian consent to participate in SHG activities, and the expectation of male villagers that such participation would benefit both the women themselves and their families and communities.

Within SHGs, there are issues of power relations. Although our groups are usually quite homogeneous, some differences may exist in education and socioeconomic status. Each group elected a president, secretary, and treasurer. It was reported in our interviews that the opinion of these women was often followed because they were trusted. At the same time, CHAT facilitators and participants stressed that the opinion of all women was considered when reaching consensus. A similar process was observed by Seshagiri et $\mathrm{al}^{44}$ when small groups were asked to solve specific tasks (in a village in the Indian Karnataka state): the more educated members and those that were more articulate had more influence solving the tasks, who nonetheless tried to actively engage "weaker" members in the activity. We conclude that although more educated SHG members had an influence on the group's decisions in our study, they did not hijack the decision-making process, as decisions were taken with consent of all group members. On the whole, interactive and continuous engagement in three rounds of CHAT exercise and exposure to insurance education have provided the SHG women an opportunity to be socially empowered.

\section{Limitations of the study}

The small number of in-depth interviews conducted does not allow the claim that they were generally representative; we therefore also triangulated this source with the findings from the CHAT exercises and exit questionnaires. The interviews were conducted by researchers employed by the partner NGOs; this might have affected respondents' comments on 
the CHAT process facilitated by these NGOs. On the other hand, respondents might have been more responsive during the interviews because they were familiar with the local researchers and the NGO.

Most of the SHGs in which we conducted CHAT have been operating for years and are used to collaborate and make decisions in group settings. This could have facilitated the CHAT process.

\section{Conclusion and policy ramifications}

This study offers clear empirical evidence that people living in rural informal settings, some of whom are illiterate and innumerate and with no prior experience with health insurance, can reach consensus on the choice of their health insurance benefit-package. The subject matter is quite complex, but when presented in a game-like way, without compromising the actuarial accuracy, people can select packages within their willingness to pay and their perceived priorities for health-care coverage. The evidence suggests that group consensus can be harnessed to enhance demand for health microinsurance in the informal economy. Moreover, the people chose the benefit-packages with a clear intention that as many members of their community as possible should benefit. This suggests that people are sensitive to enhancing equity within the group and that CHAT enables them to make inclusive choices. The packages that were chosen by the three groups were in fact implemented in the three locations in the form of CBHIs that captured solvent demand, and created the supply of health insurance, neither of which existed previously.

The question might be raised whether it is necessary to conduct CHAT exercises and consensus building in each village separately. The evidence from our field experiments points that when a population group is introduced to the concept of $\mathrm{CBHI}$ for the first time, following this process is important as it creates the basic sense of empowerment and relevance that cannot be achieved in another way. However, in a region where $\mathrm{CBHI}$ has been introduced and is perceived as successful, neighboring villages may well wish to join the same scheme without elaborate preparations. Such villages would be involved in the entire process, along with others, when major changes in the benefit-package are contemplated.

It is noted that harnessing the collective action in a manner described in this article did not occur spontaneously. It required catalytic facilitation by devoted and knowledgeable persons who guide the process at village level from inception, who first collected relevant information in the field, translated it to actuarial estimates of premiums for different benefits, and then guided the community discussions. This process can be replicated anywhere in the informal sector, provided that the similar catalytic actor/change-maker can lead communities to assume the role of market-makers of their own health insurance.

\section{Acknowledgments}

David M Dror, Pradeep Panda, and Christina May gratefully acknowledge funding provided by the European Commission 7th Framework Program, grant ID HEALTHF2-2009-223518 - Community-based Health Insurance in India. The authors gratefully acknowledge the extensive substantive contribution of the MIA and its staff in data collection and cleaning as well as in analytical inputs; the useful involvement of Ralf Radermacher in the early stages of the baseline study and pre-implementing preparations; the contribution of Katja Roth to the development of the qualitative tools; the contribution of Manish Kumar in providing essential explanations on how the preparation of the CHAT process actually unfolded in the field; the contribution of Lucy Firth to reviewing the analysis in this article and offering many useful suggestions and comments; and the implementing partners (BAIF, Shramik Bharti, and Nidan) as well as the respondents, for their ongoing willingness to share information on the implementation.

\section{Author contributions}

DD conceptualized the study and drafted the manuscript. PP and DD prepared the tools for quantitative surveys, and $\mathrm{CM}$ and PP prepared the qualitative tools. PP managed the data collection and provided oversight for study implementation. AM, PP, and CM conducted the data analyses. RK contributed to interpretation of data. DD, PP, RK, and CM critically reviewed the manuscript. All authors provided comments (including write-up) and approved the final manuscript.

\section{Disclosure}

The authors report no conflicts of interest in this work.

\section{References}

1. Bacchetta M, Ekkehard E, Bustamante J. Globalization and Informal Jobs in Developing Countries. International Labour Organization. 2009 Available from: http://www.rynekpracy.pl/pliki/pdf/34.pdf. Accessed July 21, 2014.

2. Pratap S, Quintin E. The informal sector in developing countries: Output, assets and employment (No. 2006/130). Research Paper, UNU-WIDER, United Nations University (UNU). 2006. Available from: http://www wider.unu.edu/publications/working-papers/research-papers/2006/ en_GB/rp2006-130/_files/78091818591914218/default/rp2006-130. pdf. Accessed July 21, 2014.

3. International Labour Organisation. The Informal Sector UN. Bangkok 2000. Available at http://www.ilo.org/public/english/region/asro/ bangkok/feature/inf_sect.htm May 2013. Accessed July 21, 2014. 
4. International Labour Organization [homepage on the Internet]. World Labour Report 2000: income security and social protection in a changing world. Geneva: International Labour Organization; 2000. Available from: http://www.ilo.org/public/english/protection/socsec/wlrblurb. htm. Accessed July 7, 2014.

5. Biener C, Eling M. Insurability in microinsurance markets: an analysis of problems and potential solutions. Geneva Papers. 2012;37(1): 77-107.

6. Borghi J, Maluka S, Kuwawenaruwa A, et al. Promoting universal financial protection: a case study of new management of community health insurance in Tanzania. Health Res Policy Syst. 2013;11(1):21.

7. Mahal A, Krishnaswamy K, Ruchismita R, Babu BG. What is a health card worth? A randomised controlled trial of an outpatient health insurance product in rural India. Lancet. 2013;381:S87.

8. McCord MJ, Steinmann R, Tatin-Jaleran C, Ingram M, Mateo M. The Landscape of Microinsurance in Africa 2012. Munich Re Foundation and GIZ-Program Promoting Financial Sector Dialogue in Africa; 2012. Available from: http://www.microinsurancenetwork.org/publication/ fichier/The_Landscape_of_MI_in_Africa_2012_full_study_web.pdf. Accessed July 7, 2014.

9. McCord MJ, Tatin-Jaleran C, Ingram M. The landscape of microinsurance in Latin America and the Caribbean. Multilateral Investment Fund; Citi Foundation; Microinsurance Centre; Munich Re Foundation; 2012. Available from: http://www.microinsurancecentre.org/resources/documents/market-development/the-landscape-of-microinsurance-in-latinamerica-and-the-caribbean.html. Accessed July 16, 2014.

10. Roth J, McCord MJ, Liber D. The Landscape of Microinsurance in the World's Poorest 100 Countries. Appleton: The Microinsurance Centre; 2007. Available from: http://www.microfinancegateway.org/gm/document-1.9.29195/40285_file_15.pdf. Accessed April 10, 2014.

11. Tabor SR. Community-Based Health Insurance and Social Protection Policy. Washington DC: The World Bank; 2005. Available from: http:// siteresources.worldbank.org/SOCIALPROTECTION/Resources/0503. pdf. Accessed April 10, 2014.

12. Dror DM, Jacquier C. Micro-insurance: extending health insurance to the excluded. Int Soc Secur Rev. 1999;52(1):71-97.

13. Dror DM. Health microinsurance in developing countries. In: Culyer AJ, editor. Encyclopedia of Health Economics. Vol 1. San Diego: Elsevier; 2014:412-421.

14. Dror DM, Firth L. The demand for (micro) health insurance in the informal sector. Geneva Papers. In press 2014.

15. Booske BC, Sainfort F, Hundt AS. Eliciting consumer preferences for health plans. Health Serv Res. 1999;34(4):839-854

16. Chakraborty G, Ettenson R, Gaeth G. How consumers choose health insurance. J Health Care Mark. 1994;14(1):21-33.

17. Harris KM, Keane MP. A model of health plan choice: inferring preferences and perceptions from a combination of revealed preference and attitudinal data. J Econom . 1998;89(1-2):131-157.

18. Kerssens JJ, Groenewegen PP. Consumer preferences in social health insurance. Eur J Health Econ. 2005;6(1):8-15.

19. Mechanic D. Consumer choice among health insurance options. Health Aff (Millwood). 1989;8(1):138-148.

20. Van den Berg B, Van Dommelen P, Stam P, Laske-AldershofT, Buchmueller T, Schut FT. Preferences and choices for care and health insurance. Soc Sci Med. 2008;66(12):2448-2459.

21. Scanlon DP, Chernew M, Lave JR. Consumer health plan choice: current knowledge and future directions. Annu Rev Public Health. 1997;18(1):507-528.

22. De Allegri M, Sanon M, Bridges J, Sauerborn R. Understanding consumers' preferences and decision to enrol in community-based health insurance in rural West Africa. Health Policy. 2006;76(1):58-71.

23. Harms J. Microinsurance Product Design: consumer preferences in Kenya. Geneva: ILO and Microinsurance Innovation Facility; 2011. Available from: http://www.ilo.org/public/english/employment/ mifacility/download/repaper4.pdf. Accessed July 7, 2014.
24. Onwujekwe O, Onoka C, Uguru N, et al. Preferences for benefitpackages for community-based health insurance: an exploratory study in Nigeria. BMC Health Serv Res. 2010;10:162-162.

25. Dror DM, Koren R, Ost A, Binnendijk E, Vellakkal S, Danis M. Health insurance benefit-packages prioritized by low-income clients in India: three criteria to estimate effectiveness of choice. Soc Sci Med. 2007;64(4):884-896.

26. Danis M, Binnendijk E, Vellakkal S, Ost A, Koren R, Dror DM. Eliciting health insurance benefit choices of low income groups. Econ Polit Wkly. 2007;42(32):3331-3339.

27. Micro Insurance Academy. Developing Efficient and Responsive Community-Based Health Insurance in India. Available from: http:// www.microinsuranceacademy.org/project/uttar-pradesh-and-biharindia/. Accessed July 21, 2014.

28. Doyle C, Panda P, Poel EV de, Radermacher R, Dror DM. Reconciling research and implementation in micro health insurance experiments in India: study protocol for a randomized controlled trial. Trials. 2011;12(1):224

29. Panda P, Chakraborty A, Dror DM, Bedi AS. Enrolment in communitybased health insurance schemes in rural Bihar and Uttar Pradesh, India. Health Policy Plan. Epub October 26, 2013.

30. Tesoriero F. Strengthening communities through women's self help groups in South India. Community Dev J. 2006;41(3):321-333.

31. Craig G. Towards the Measurement of Empowerment: the Evaluation of Community Development. Community Dev Soc J. 2002;33(1): 124-146.

32. Toomey AH. Empowerment and disempowerment in community development practice: eight roles practitioners play. Community Dev J. 2011;46(2):181-195.

33. Indian Council of Medical Research. Ethical Guidelines for Biomedical Research on Human Participants. New Delhi: Indian Council of Medical Research; 2006. Available from: http://icmr.nic.in/ethical_guidelines. pdf. Accessed July 7, 2014.

34. Hsieh H-F, Shannon SE. Three approaches to qualitative content analysis. Qual Health Res. 2005;15(9):1277-1288.

35. Panda P, Chakraborty A, Dror DM. Building awareness to health insurance among the target population of community-based health insurance schemes in rural India. Social Science and Medicine. In press 2014.

36. Sultana P, Thompson P. Methods of consensus building for communitybased fisheries management in Bangladesh and in the Mekong Delta. Agricultural Systems. 2004;82:327-353.

37. Mohammed S, Ringseis E. Cognitive diversity and consensus in group decision making: the role of inputs, processes, and outcomes. Organ Behav Hum Decis Process. 2001;85(2):310-335.

38. Kader GD, Perry M. Variability for categorical variables. J Stat Educ. 2007;15(2).

39. Ostrom E. Collective action and the evolution of social norms. J Econ Perspect. 2000;14(3):137-158.

40. Dror DM. Why “one-size-fits-all” health insurance products are unsuitable for low-income persons in the informal economy in India. Asian Econ Rev. 2007;49(1):47-56.

41. Nyman JA. The Theory of Demand for Health Insurance. Stanford Univ Press 2003. Available from http://www.sup.org/search/blogthis. cgi?search=0804744882. Accessed July 16, 2014.

42. Pauly MV, Blavin FE, Meghan S. How private health insurance can work in developing countries. Health Affairs. 2009;28(6):1778-1787.

43. Baily S. Deconstructing gatekeepers discourses in the establishment of self-help groups for women in rural India. Community Dev J. Epub November 28, 2013.

44. Seshagiri S, Kaduskar MV, Bhaskaran P. Understanding group communication in rural India. In: Proceedings of the 7 th Nordic Conference on Human-Computer Interaction: Making Sense through Design. NordiCHI '12. New York: ACM; 2012:617-626. 


\section{Supplementary materials}

Table SI Socioeconomic and demographic profile of the CHAT participants

\begin{tabular}{lllll}
\hline & Pratapgarh & Kanpur-Dehat & Vaishali & All combined \\
\hline Average age, years (SEM) & $4 I(0.59)$ & $39(0.65)$ & $36(0.50)$ & $39(0.33)$ \\
Married, \% & 88.0 & 86.4 & 94.1 & 90.0 \\
Hindu, \% & 86.6 & 92.9 & 97.9 & 92.8 \\
Scheduled caste and scheduled tribe, \% & 41.5 & 26.0 & 41.8 & 37.5 \\
Average years of education (SEM) & $2.2(0.19)$ & $3.5(0.22)$ & $2.3(0.16)$ & $2.6(0.11)$ \\
Self-employed, \% & 15.5 & 19.0 & 13.9 & 15.8 \\
Wage employment, \% & 19.0 & 6.0 & 14.1 & 13.5 \\
Average monthly per capita & $1,147(30.45)$ & $1,776(71.02)$ & $1,377(43.47)$ & $1,408(28.53)$ \\
expenditure, INR (SEM) & & & & \\
$\mathrm{N}$ & 432 & 352 & 525 & 1,309 \\
\hline
\end{tabular}

Abbreviations: CHAT, Choosing Healthplans All Together; INR, Indian Rupee; SEM, standard error of the mean.
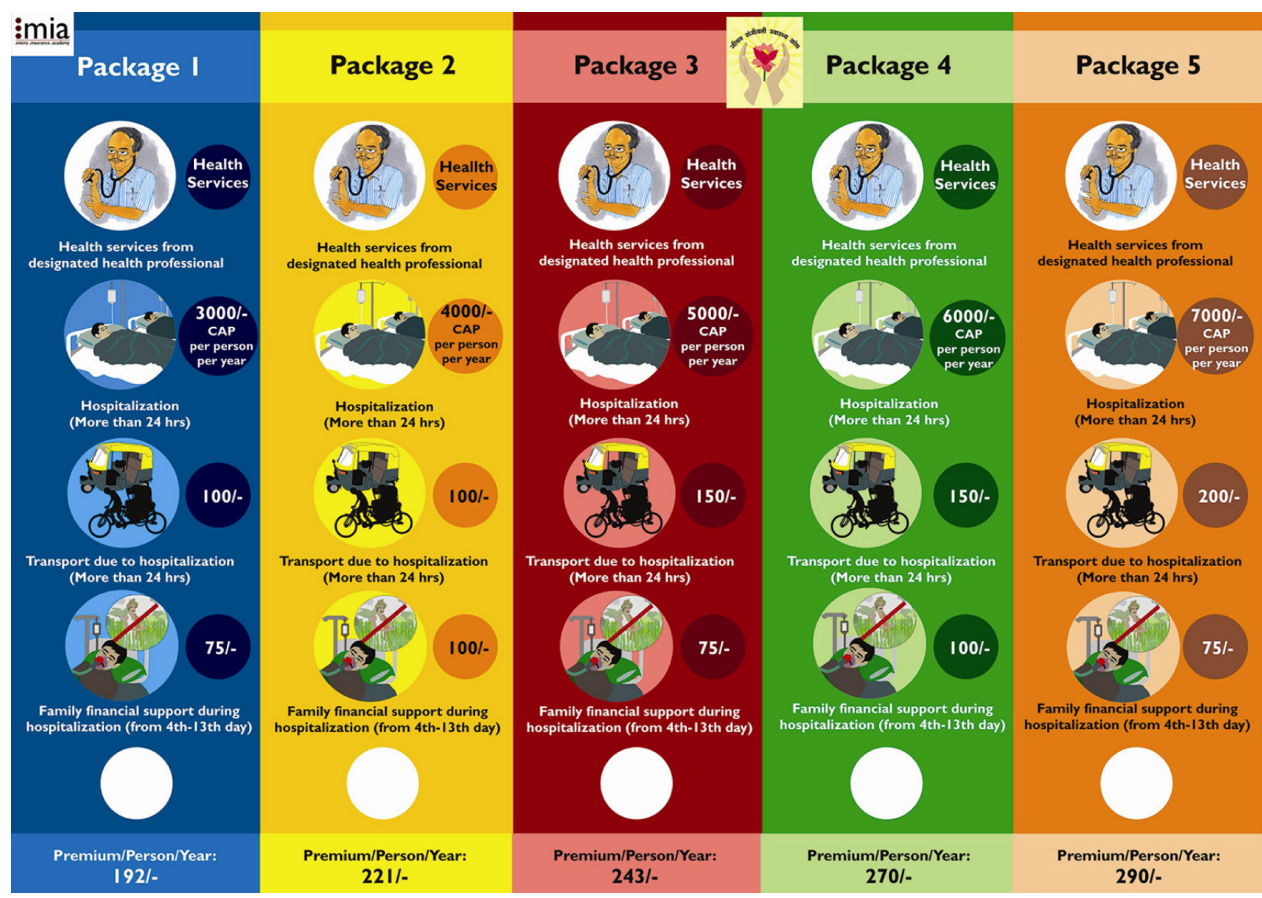

Figure SI CHAT board used in Kanpur-Dehat.

Abbreviation: CHAT, Choosing Healthplans All Together. 


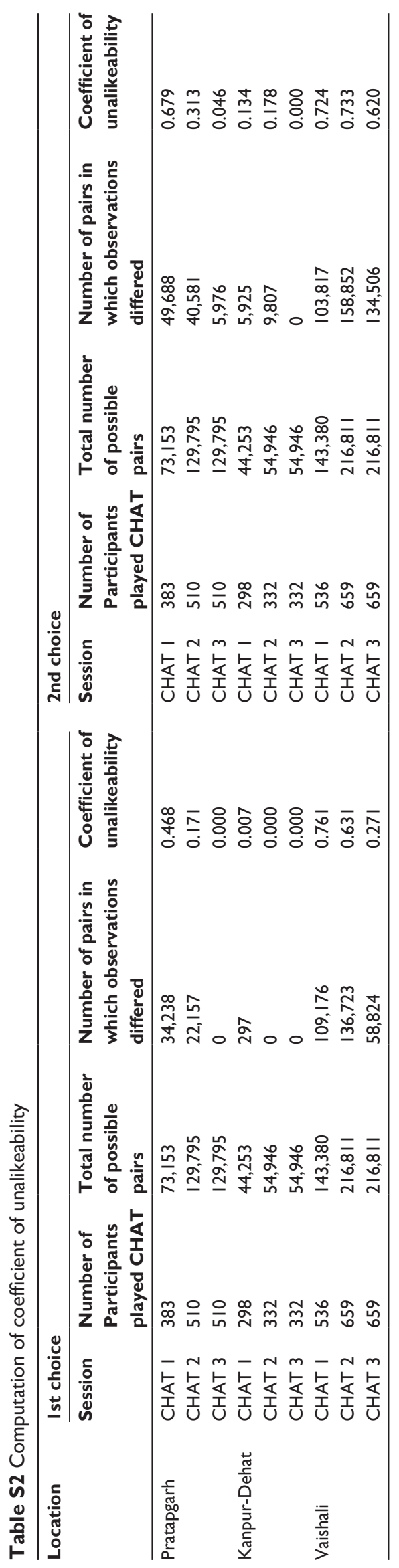


Risk Management and Healthcare Policy

Dovepress

\section{Publish your work in this journal}

Risk Management and Healthcare Policy is an international, peerreviewed, open access journal focusing on all aspects of public health, policy, and preventative measures to promote good health and improve morbidity and mortality in the population. The journal welcomes submitted papers covering original research, basic science, clinical \& epidemio- logical studies, reviews and evaluations, guidelines, expert opinion and commentary, case reports and extended reports. The manuscript management system is completely online and includes a very quick and fair peerreview system, which is all easy to use. Visit http://www.dovepress.com/ testimonials.php to read real quotes from published authors.

\footnotetext{
Submit your manuscript here: http://www.dovepress.com/risk-management-and-healthcare-policy-journal
} 